\title{
New Curcumin Analog, CCA-1.1, Synergistically Improves the Antiproliferative Effect of Doxorubicin Against T47D Breast Cancer Cells
}

Febri Wulandari' ${ }^{1}$ Muthi' Ikawati1,2, Dhania Novitasari1, Mitsunori Kirihata ${ }^{3}$, Jun-Ya Kato ${ }^{4}$, Edy Meiyanto ${ }^{1,2 *}$

1. Cancer Chemoprevention Research Center, Faculty of Pharmacy, Universitas Gadjah Mada (UGM), Sekip Utara, Yogyakarta 55281, Indonesia

2. Macromolecular Engineering Laboratory, Department of Pharmaceutical Chemistry, Faculty of Pharmacy UGM, Sekip Utara, Yogyakarta 55281, Indonesia

3. Research Center of Boron Neutron Capture Therapy, Research Organization for the $21^{\text {st }}$ Century, Osaka Prefecture University, 1-1 Gakuen-Cho, Nakaku, Sakai, Osaka 599-8531, Japan

4. Laboratory of Tumor Cell Biology, Division of Biological Science, Graduate School of Science and Technology, Nara Institute of Science and Technology, 8916-5 Takayama, Ikoma, Nara 630-0101, Japan

\begin{tabular}{l} 
Info Article \\
\hline Submitted: $07-09-2020$ \\
Revised: $07-10-2020$ \\
Accepted: $15-12-2020$ \\
*Corresponding author \\
Edy Meiyanto \\
Email: \\
edy_meiyanto@ugm.ac.id
\end{tabular}

\section{INTRODUCTION}

Chemoprevention-curcumin analog 1.1, a new curcumin analog derived from PGV-1, (CCA1.1; Figure. 1) (Utomo et al., 2020) shows potential inhibitory effects against several cancer cells, including T47D breast cancer cells compared with its lead compound. CCA-1.1 has been reported to interact with several types of target proteins, such as HER2, EGFR, IKK, and ER (Utomo et al., 2020), in silico. A recent study showed that CCA-1.1 stimulates apoptosis, G2/M phase disruption, intracellular reactive oxygen species (ROS) generation, and senescence induction in human colon cancer WiDr cells (Wulandari et al., 2020). PGV-1, the lead compound, demonstrates strong inhibitory effects via ROS advancement in 4T1 (Meiyanto et al., 2019), a triple-negative breast cancer cell line. The inhibitory target of PGV-1 in T47D breast cancer cells appears to be the microtubule, in which hyperploid formation is induced and apoptosis is increased (Da'i et al., 2007). These phenomena distinguish from PGV-1 that stimulated cell cycle arrest specifically at prometaphase in K562 cells (Lestari et al., 2019) 
but differ from curcumin (Lee \& Langhans, 2012) and even anti-microtubule drugs (Bates \& Eastman, 2017). Furthermore, PGV-1 displays cochemotherapeutic effects by increasing the cytotoxic activities of doxorubicin (Dox) and 5-FU in HER2-overexpressing breast (MCF7/HER2) and WiDr cancer cells (Meiyanto et al., 2018), respectively; indeed, PGV-1 could even increase the sensitivity of Dox-resistant breast cancer cells (Meiyanto et al., 2014). Because CCA-1.1 features a chemical properties that may be essential for its development into a therapeutic dosage form for clinical usage (Utomo et al., 2020), the possibility of CCA-1.1 mimicking the anticancer activities of PGV1 should be considered in explorations of potential anti-breast cancer therapy candidates.<smiles>Cc1cc(/C=C2\CC/C(=C\c3cc(C)c(O)c(C)c3)C2=O)cc(C)c1O</smiles><smiles>Cc1cc(/C=C2\CC/C(=C\c3cc(C)c(O)c(C)c3)C2O)cc(C)c1O</smiles>

Figure 1. Chemical structures of the compounds of interest. (A) Pentagamavunone-1 (PGV-1; 2,5-bis(4-hydroxy-3,5-dimethylbenzylidene)-

cyclopentanone) and (B) CCA-1.1 (2,5-bis-(4hydroxy-3,5-dimethylbenzylidene) cyclopentanol).

Breast cancer is an extremely heterogeneous disorder comprising numerous genetic and epigenetic alterations with various clinical characteristics (Griffith et al., 2018). Thus, obtaining new anticancer drugs with a targeted mechanism poses significant challenges. Most human breast cancers are classified as estrogen receptor-positive (ER+) (Kelly et al., 2017). While noticeable changes in hormone expression may be used as molecular markers, breast cancer is also propelled by genomic instability (GI) (Abbas et al., 2013) and influenced by the tumor microenvironment (Lal et al., 2017). This complexity is a critical factor in choosing a suitable experimental model because in vitro studies consistently utilize cell lines as tools
(Holliday and Speirs, 2011; Kao et al., 2009). The hormone-dependent T47D cell line is known as a luminal A subtype of the ER+ human breast cancer cell line (Yu et al., 2017, p. 47). T47D cells are characterized by mutations in $p 53$ and have aneuploid chromosomes (Yu et al., 2017). The mutation in the $p 53$ gene is the most frequent trigger for genetic alterations in human cancers that regulates various biological functions, including cell cycle progression, senescence, proliferation, DNA repair, and apoptosis (Griffith et al., 2018). T47D cells develop improperly aligned chromosomes by failing to undergo mitosis, leading to aneuploidy or polyploidy (Chen and Ni, 2006; Otto, 2007). Therefore, the T47D cell line is an appropriate model to assess and compare the anticancer effects of CCA-1.1 alone and in combination with Dox with those of PGV-1. This study intended to constitute the activity of CCA-1.1 as a chemotherapeutic agent, especially in terms of the cell cycle, ROS-related apoptosis, and senescence against ER+ breast cancer. The results will provide new extensive confirmation of CCA-1.1 as a single and co-chemotherapeutic agent for ER+ breast cancer.

\section{MATERIALS DAN METHODS Chemicals and Cell Lines}

CCA-1.1 and PGV-1 were provided by the Cancer Chemoprevention Research Center (Utomo et al., 2020), Faculty of Pharmacy, UGM. The T47D cell line was obtained from Nara Institute of Science and Technology, Japan, and maintained in DMEM supplemented with $1 \%$ penicillin-streptomycin (Gibco), 10\% (v/v) FBS (Sigma), sodium bicarbonate (Sigma), and HEPES (Sigma).

\section{Cytotoxic Assay}

T47D cells $\left(7 \times 10^{3}\right.$ cells/well $)$ were plated onto 96-well plates and treated with CCA1.1, PGV-1, Dox, and the combination of CCA-1.1 and Dox at different concentrations. Following $24 \mathrm{~h}$ of treatment, each well was added with $0.5 \mathrm{mg} / \mathrm{mL}$ of MTT reagent (Sigma) in DMEM and then incubated for another $3 \mathrm{~h}$. The MTT reaction was terminated by addition of stopper reagent $(10 \%$ Sodium dodecyl sulfate (Merck) in $\mathrm{HCl} 0.01 \mathrm{~N}$ (Merck)) and overnight incubation. The absorbance of the wells was measured using a microplate reader (BioRad) at $595 \mathrm{~nm}$. The corresponding $\mathrm{IC}_{50}$ and combination index (CI) value were then calculated. 
(A)

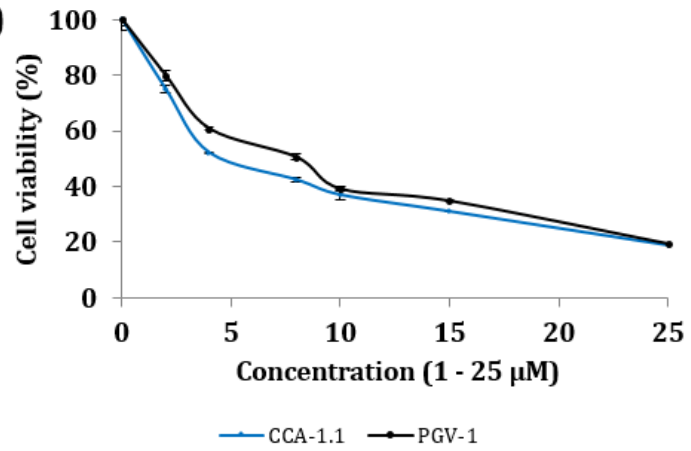

(C)

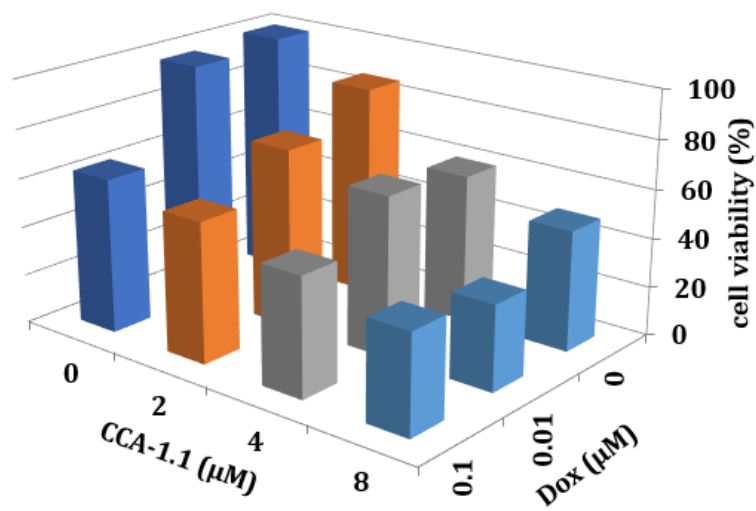

(B)

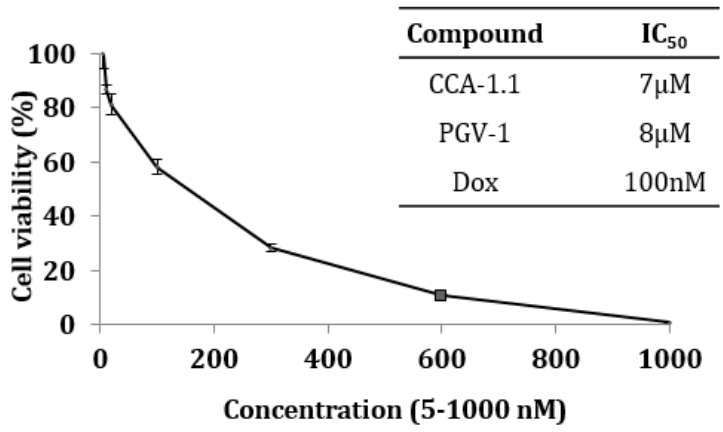

(D)

\begin{tabular}{ccc}
\hline \multirow{2}{*}{ CCA-1.1 $(\boldsymbol{\mu M})$} & \multicolumn{2}{c}{ Dox $(\boldsymbol{\mu M})$} \\
\cline { 2 - 3 } & $\mathbf{0 . 0 1}$ & $\mathbf{0 . 1}$ \\
\hline $\mathbf{2}$ & 0.82 & 0.27 \\
$\mathbf{4}$ & 0.81 & 0.39 \\
$\mathbf{8}$ & 0.55 & 0.63 \\
\hline
\end{tabular}

Figure 2. Cytotoxic effect on T47D growth profile of CCA-1.1, PGV-1 (A), doxorubicin (Dox) (B), combination of CCA-1.1 with Dox (C), and CI values. An amount of $7 \times 10^{3}$ cells/well were treated by CCA-1.1, PGV-1, and doxorubicin for $24 \mathrm{~h}$ as described in the Method section. The data was presented as average \pm standard error (SE) $(n=3)$.

\section{Cell Cycle Analysis}

Cells were plated on six-well plates at a density of $2 \times 10^{5}$ cells/well, treated with CCA-1.1, PGV-1 (4 or $8 \mu \mathrm{M})$ or $100 \mathrm{nM}$ Dox, and cultured for $24 \mathrm{~h}$. Cell pellets were generated by centrifugation, collected, and washed with buffer solution. Propidium iodide staining was carried out according to the manufacturer of the BD Cycletest ${ }^{\mathrm{TM}}$ Plus DNA Kit (USA) and analyzed using a BD Accuri $^{\mathrm{TM}}$ C6 flow cytometer (BD Bioscience).

\section{Apoptosis Assay}

Annexin-V-propidium iodide (PI) reagent was used to analyze apoptosis. Briefly, cells were plated on six-well plates at a density of $2 \times 10^{5}$ cells/well and treated with CCA-1.1, PGV-1, or Dox for 24h. Centrifugation was conducted to collect the cells, which were subsequently stained for $10 \mathrm{~min}$. Apoptotic cells were finally determined by flow cytometry.

\section{DCFDA Staining ROS-based assay}

T47D cells were plated on 24-well plates at a density of $5 \times 10^{4}$ cells/well and cultured overnight. The medium was removed, and the cells were collected in $1 \times$ supplemented buffer $500 \mu \mathrm{L}$ (FBS $10 \%$ in PBS) by trypsin EDTA. The cells were stained for $30 \mathrm{~min}$ with $25 \mu \mathrm{M}$ DCFDA (Sigma) and then treated with CCA-1.1 alone, PGV-1 (4 or $8 \mu \mathrm{M})$ alone, or CCA-1.1 with Dox for $4 \mathrm{~h}$. Intracellular ROS levels in the cell suspensions were then measured by the BD Accuri $\mathrm{C}^{\mathrm{TM}}$ flow cytometer.

\section{SA- $\beta$-Gal Senescence Assay}

T47D cells $\left(2 \times 10^{5}\right.$ cells/well $)$ were plated on a six-well plate overnight. A series of concentrations of CCA-1.1, PGV-1, and the combination of CCA-1.1 and Dox was added to the cells, and incubation was carried out for $24 \mathrm{~h}$. The cells were washed with PBS, fixed for $20 \mathrm{~min}$, and 
then added with $1-2 \mathrm{~mL}$ of staining solution. The plate was incubated for three days at $37^{\circ} \mathrm{C}$. $\beta$-Galactosidase (Gal)-positive cells (green) were observed under an inverted microscope (CKX-41 Olympus).

\section{Data analysis}

Cytotoxicity study was analysed by determining IC $_{50}$ value. Cell cycle distribution, apoptosis, and ROS level were acquired by using BD C6 Flowcytometry. Data presented as mean \pm SD, followed by statistical analysis using Student's ttest. $\mathrm{P}$-values $\left({ }^{*} p<0.05 ;{ }^{* *} p<0.01\right)$ are included in each Figure accordingly.

\section{RESULTS AND DISCUSSION}

Effects of Single and Combination Treatment of CCA-1.1, PGV-1, and Doxorubicin on T47D Cells

This study aimed to establish the activity of CCA-1.1 as a prospective single or co-chemotherapeutic agent, particularly in combination with Dox. Thus, we evaluated the biological effects of this new curcumin analog alone and in combination with Dox on ER+ breast cancer cells. First, we used the MTT assay to assess the cytotoxic effect of CCA-1.1 alone on T47D cells in comparison with that of PGV-1 as the reference compound, beside Dox as the chemotherapeutic model. CCA-1.1 and PGV-1 showed similar cytotoxic effects. The $\mathrm{IC}_{50}$ values of CCA-1.1, PGV-1, and Dox were $7 \mu \mathrm{M}$, $8 \mu \mathrm{M}$, and $100 \mathrm{nM}$, respectively (Figure 2). These results reveal that CCA-1.1 has effects equivalent to those of PGV-1 and could be developed as an anticancer candidate for ERpositive breast cancer.

Dox is known as the standard chemotherapeutic drug for breast cancer but induces several adverse effects and, eventually, drug resistance (Bandyopadhyay et al., 2010). Combinatorial therapy is often carried out to increase the efficacy of cancer treatment (Reynolds \& Maurer, 2005). Thus, we co-treated T47D cells with Dox and a series of different concentrations of CCA-1.1. The results showed that the combination treatment of CCA-1.1 and Dox at the $\mathrm{IC}_{50}$ concentration (100nM, 24h) decreases cell viability by up to $50 \%$ (Figure 2). All of the combination treatments showed synergistic effects $(\mathrm{CI}<0.9)$. This finding indicates that CCA-1.1 shows improved cytotoxic effects in combination with Dox.

\section{Effects of CCA-1.1 and Doxorubicin Treatment on the Cell Cycle Profile of T47D Cells}

Because cell cycle progression is the cytotoxic target of PGV-1, we conducted flow cytometric analysis to observe the effects of CCA1.1 alone and in combination with Dox on the cell cycle profiles of T47D cells. Dox is a chemotherapeutic drug that typically generates cell cycle arrest at the G2/M phases. We thus expected that the cell cycle modulation of CCA-1.1 is probably equivalent to that PGV-1, which is known to cause $\mathrm{G} 2 / \mathrm{M}$ phase accumulation in numerous cancer cells, including T47D (Da'i et al., 2007). The results confirm that our compound significantly increases $\mathrm{G} 2 / \mathrm{M}$ phase accumulation $(p<0.05)$ when applied as a single treatment or in combination with Dox (Figure. 3). Interestingly, treatment with PGV-1 alone exhibited significantly more polyploid cell accumulation than treatment with CCA-1.1 $(p<0.05)$. We also noted that CCA-1.1 and PGV-1 (alone and in combination with Dox) induces sub-G1 accumulation $(p<0.05)$, which may indicate apoptosis. This result also reveals that the cytotoxic synergism of CCA-1.1 and Dox is most likely related to the increasing evidence of sub-G1 population that maybe even in conjunction with cell cycle arrest at G2/M. Thus, CCA-1.1 alone or in combination with Dox may cause cell cycle arrest leading to enhanced apoptosis.

\section{Apoptosis induction of CCA-1.1 and Dox on T47D cells}

To confirm that sub-G1 accumulation of the treatment indicated as apoptotic cells, we conducted flow cytometric assay with annexin-VPI staining. PGV-1, the reference compound of CCA-1.1, could inhibit cell growth by actively inducing apoptosis in T47D cancer cells but not in (non-cancerous) NIH-3T3 cells (Da'i et al., 2007). We found that CCA-1.1 applied at concentrations of 4 or $8 \mu \mathrm{M}$ as a single treatment or in combination with Dox $(24 \quad \mathrm{~h})$ significantly increases the apoptosis of T47D cells when compared with PGV-1 and Dox (Figure. 4). However, we found that the numbers of apoptotic cells in treatments with CCA-1.1 alone and in combination with Dox are not significantly different. This phenomenon indicates that the effect of CCA-1.1 on cell apoptosis dominates than that of Dox. These results confirm that apoptosis is correlated with cell cycle arrest (Shah and Schwartz, 2001). 
(A)
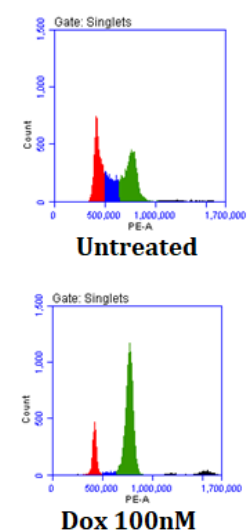
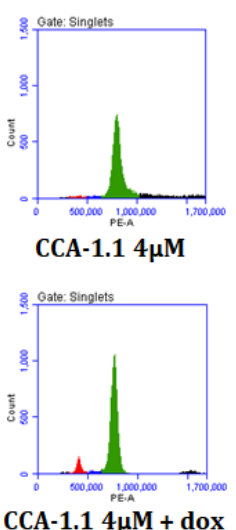

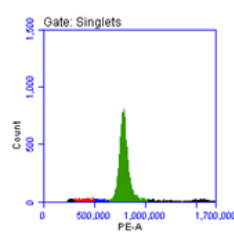

CCA-1.1 $8 \mu \mathrm{M}$

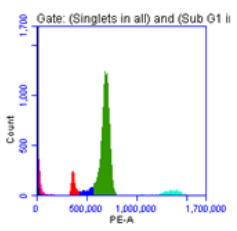

CCA-1.1 $8 \mu \mathrm{M}+$ dox

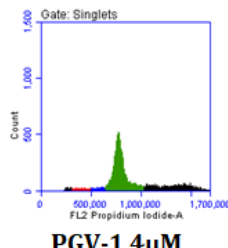

PGV-1 4 $\mu$ M

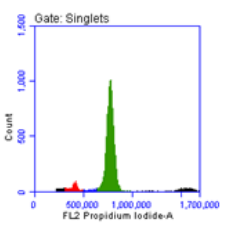

PGV-1 4 $\mu M+$ dox
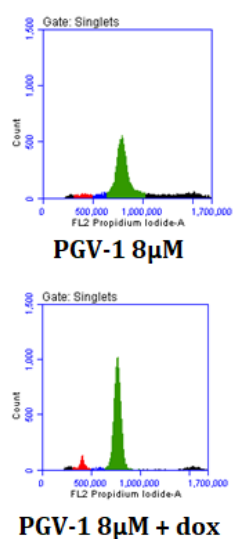

(B)

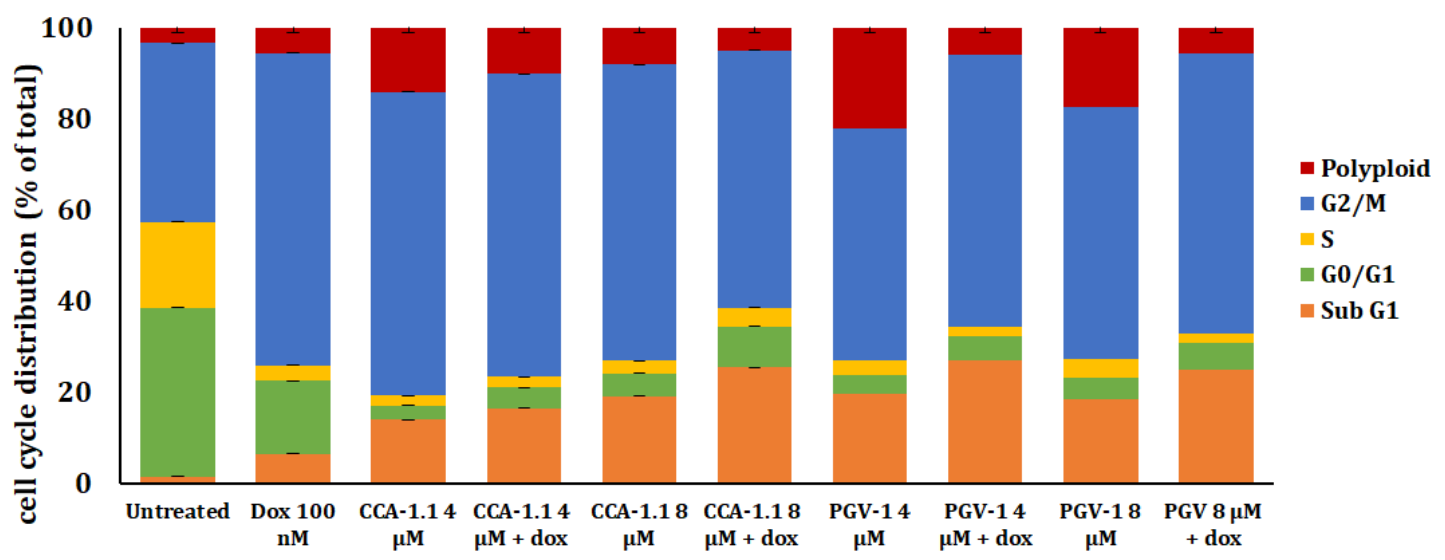

Figure 3. Effects of CCA-1.1, PGV-1, CCA-1.1 + doxorubicin (Dox) on the cell cycle profile of T47D cells. Cells $\left(2 \times 10^{5}\right.$ cells/well) were treated with CCA-1.1, PGV-1, or Dox for $24 \mathrm{~h}$, stained with PI as described in the Methods section, and then subjected to flow cytometric analysis. (A) Flow cytograms of each treatment. (B) Graph of the $\%$ cell population of each phase. The data are presented as average \pm standard deviation $(n=3)$.

In the present study, we assumed that the mechanisms of CCA-1.1 as a chemotherapeutic or co-chemotherapeutic agent would be similar to those of PGV-1, the anticancer mechanisms of which are related to cell cycle arrest and apoptosis, senescence, and ROS accumulation (Lestari et al., 2019; Meiyanto et al., 2018, 2019).

\section{Effects of CCA-1.1 and Dox Treatment on Intracellular ROS Levels in T47D Cells}

Maintenance of the appropriate intracellular ROS level is critical to the survival of a cell. ROS disrupts essential macromolecules within a cell, resulting in cell cycle arrest or apoptosis. With the active metabolism with the consequence of increasing ROS, cancer cells express ROS metabolic enzymes to compensate these phenomena
(Larasati et al., 2018; Ray et al., 2012). Chemotherapeutic agents, including Dox, can generate large amounts of ROS in cells, leading to cytotoxic effects (Tacar et al., 2013). To confirm that the effects of the test compounds on cell cycle arrest and apoptosis are related to ROS generation, we measured the ROS levels of T47D cells stained with DCFDA by flow cytometry. Dox (100 nM, $4 \mathrm{~h})$ significantly $(p<0.01)$ elevated intracellular ROS levels in T47D cells (Figure. 5). The combination of CCA-1.1 $(4 \mu \mathrm{M})$ and Dox revealed the highest ROS levels among the treatments studied $(p<0.001)$. Co-treatment of CCA-1.1 at a concentration of $8 \mu \mathrm{M}$ and Dox yielded ROS levels similar to those obtained from Dox alone. Overall, single and combination treatment of CCA-1.1 or PGV-1 yielded ROS levels higher than or at least similar to those induced by Dox. 

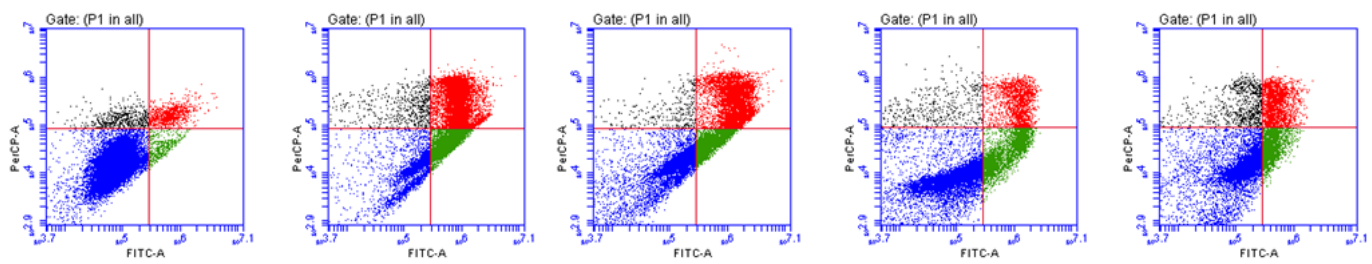

Untreated

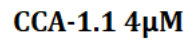

\section{CCA-1.1 8 $\mu \mathrm{M}$}
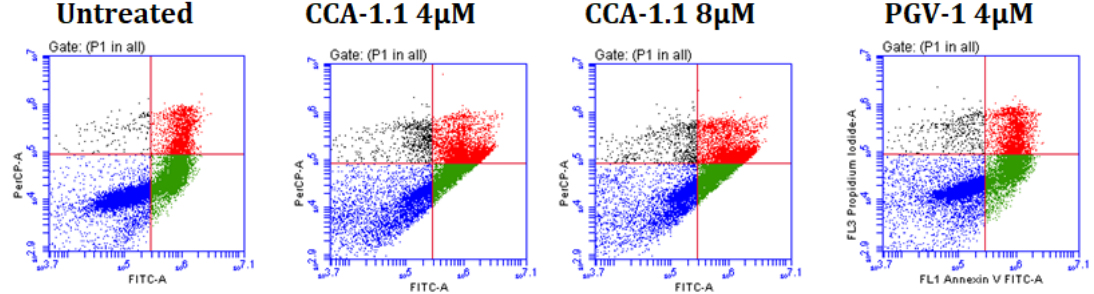

Dox 100nM

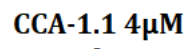

CCA-1.1 $8 \mu \mathrm{M}+$ dox

PGV-1 $4 \mu \mathrm{M}+$ dox

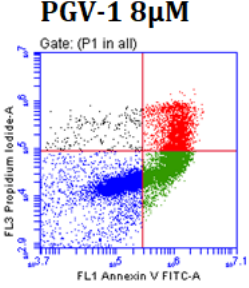

PGV-1 8 $\mu \mathrm{M}+$ dox

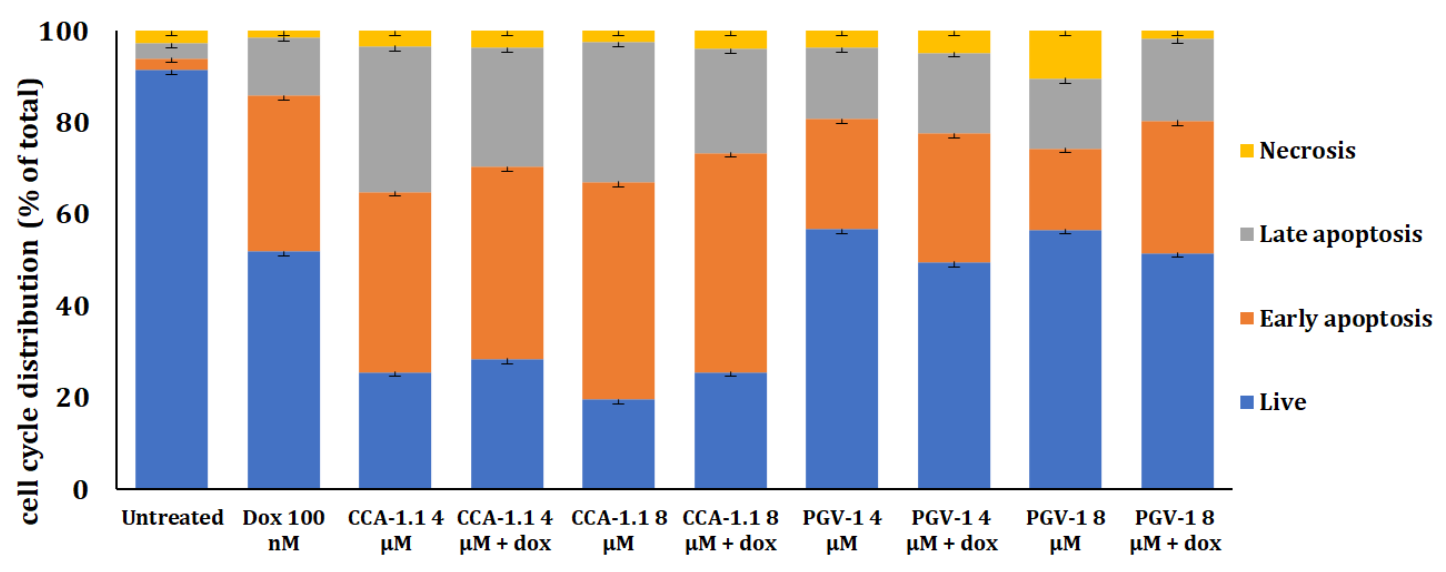

Figure 4. Effects of CCA-1.1, PGV-1, and its combination with doxorubicin (Dox)-induced apoptosis on T47D cells. Cells $\left(2 \times 10^{5}\right.$ cells $\left./ \mathrm{mL}\right)$ were incubated with CCA-1.1 and PGV-1 at a concentration of 4 or $8 \mu \mathrm{M}$ for $24 \mathrm{~h}$ and then stained with annexin-V-PI. (a) Flow cytograms of each treatment. (b) Quantification of \% apoptotic cells. The data are presented as mean \pm standard deviation $(n=3)$.

\section{Effects of CCA-1.1 and Doxorubicin Treatment on Senescence Induction}

High ROS levels in cells are usually linked to senescence induction, physiological changes of cells, whether it is not proliferating nor die (Baar et al., 2017). Senescence has been correlated with prolonged cell cycle arrest and apoptosis. To clarify our hypothesis, we conducted SA- $\beta$-Gal-based assays. Among the treatments studied, Dox, a known senescence-inducing agent, induced the most extensive $(p<0.001)$ senescence, followed by CCA-1.1 and PGV-1 in single and combination treatment, which significantly $(p<0.001)$ induced similar levels of senescence in T47D cells (Figure 6). T47D-cells treated with the test compounds displayed distinct morphological changes; for example, they grew larger and showed multiple nuclei, which indicates that the cells failed to divide. Taken together, these results demonstrate that cell cycle arrest, apoptosis, and ROS generation due to CCA-1.1 and Dox may be correlated with senescence.

T47D cells originate from mutations in p53 and feature aneuploid chromosomes (Fernandez et al., 1994; Yu et al., 2017). PGV-1 can induce T47D cell apoptosis by increasing caspase activation with polyploid transition (Meiyanto et al., 2007). 
(A)

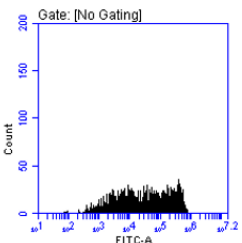

Untreated

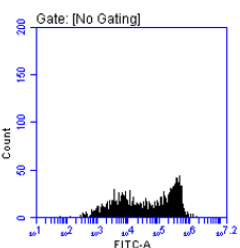

Dox 100nM

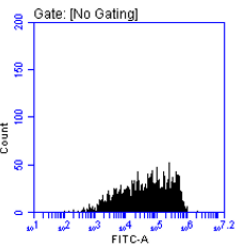

CCA-1.1 $4 \mu \mathrm{M}$

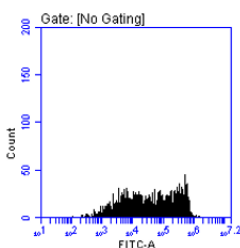

CCA-1.1 $4 \mu \mathrm{M}$

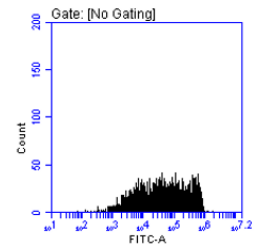

CCA-1.1 $8 \mu \mathrm{M}$

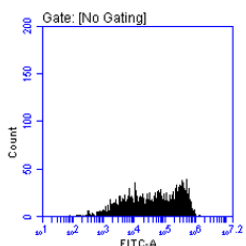

CCA-1.1 $8 \mu \mathrm{M}+$ dox

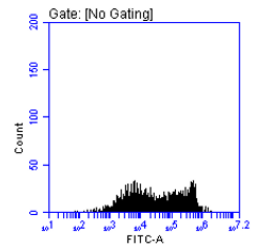

PGV-1 4 $\mu M$

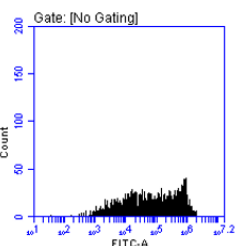

PGV-1 4 $\mu M$ + dox

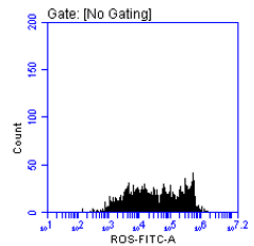

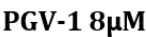

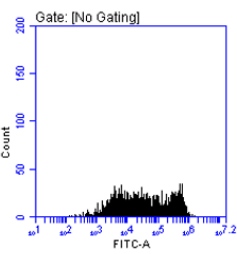

PGV-1 8uM + dox

(B)

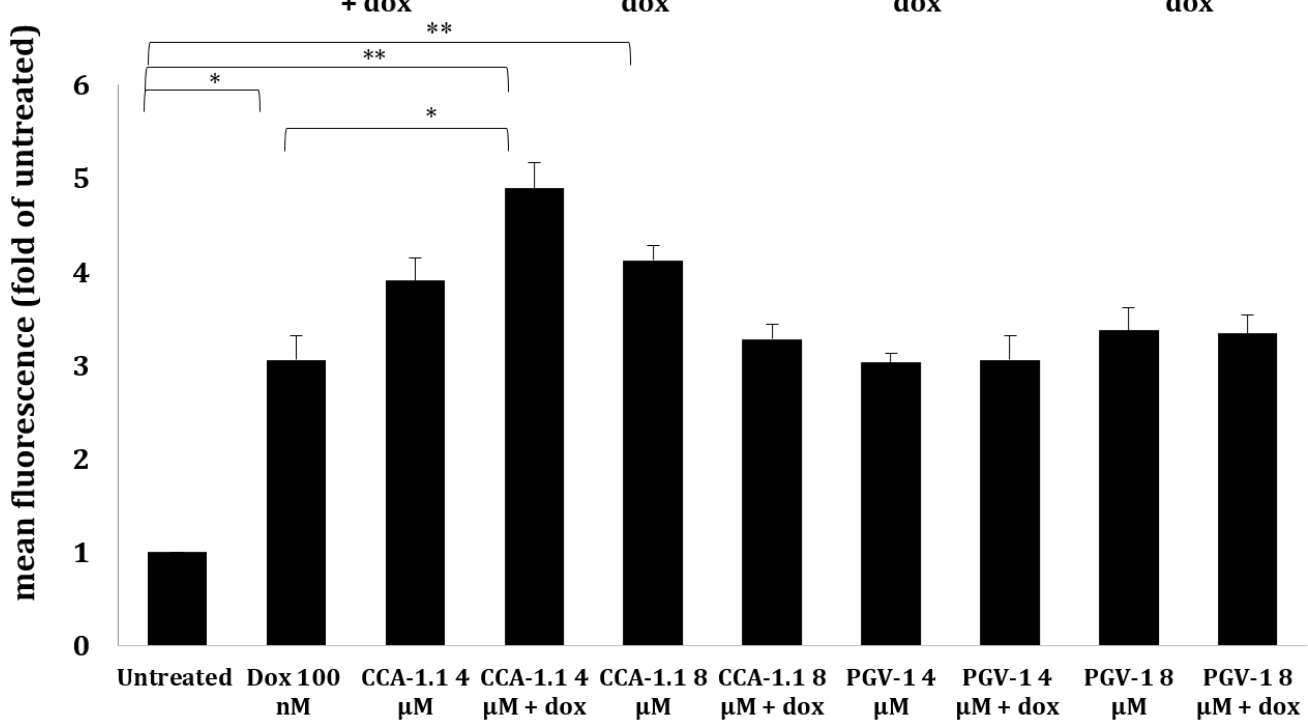

Figure 5. Effects of CCA-1.1, PGV-1, and CCA-1.1 + doxorubicin (Dox) on intracellular ROS accumulation in T47D cells. (A) Flow cytograms and (B) graph of ROS levels. Cells $\left(5 \times 10^{4}\right.$ cells/well) were incubated with CCA-1.1 or PGV-1 at a concentration of 4 or $8 \mu \mathrm{M}$ for $4 \mathrm{~h}$ and stained with DCFDA. ROS measurement was carried out by flow cytometry. The data are presented as mean fluorescence \pm SE $(n=3)$. Differences among treatments were analyzed using Student's $t$-test $\left({ }^{*} p<0.01 ;{ }^{* *} p<0.001\right)$.

This study aimed to observe and compare the cytotoxic effects of CCA-1.1 alone and in combination with Dox with those of PGV-1. An exciting result of this research is that CCA-1.1 not only has cytotoxic effects equivalent to those of PGV-1 but also shows cytotoxic potentiation with Dox. This co-treatment effect has significant synergistic characteristics and reveals that our target compound can be further developed as a single or co-chemotherapeutic agent with Dox. Previous studies revealed that PGV-1 exerts synergistic effects with Dox and 5-FU on T47D and MCF7 (Da'i et al., 2007; Hermawan et al., 2011) and
WiDr cancer cells (Meiyanto et al., 2018). Therefore, the synergistic effect of CCA-1.1 may also be applicable to other types of cancer cells. Combination therapy is expected to provide more effective treatments for cancer with fewer adverse effects.

Our findings suggest that the synergistic effects of the combination treatment may be related to enhancements in apoptosis. Cell cycle analysis revealed an increase in the population of cells in the sub-G1 phase. However, this profile does not match the results of apoptosis determined by annexin-V staining. 
(A)
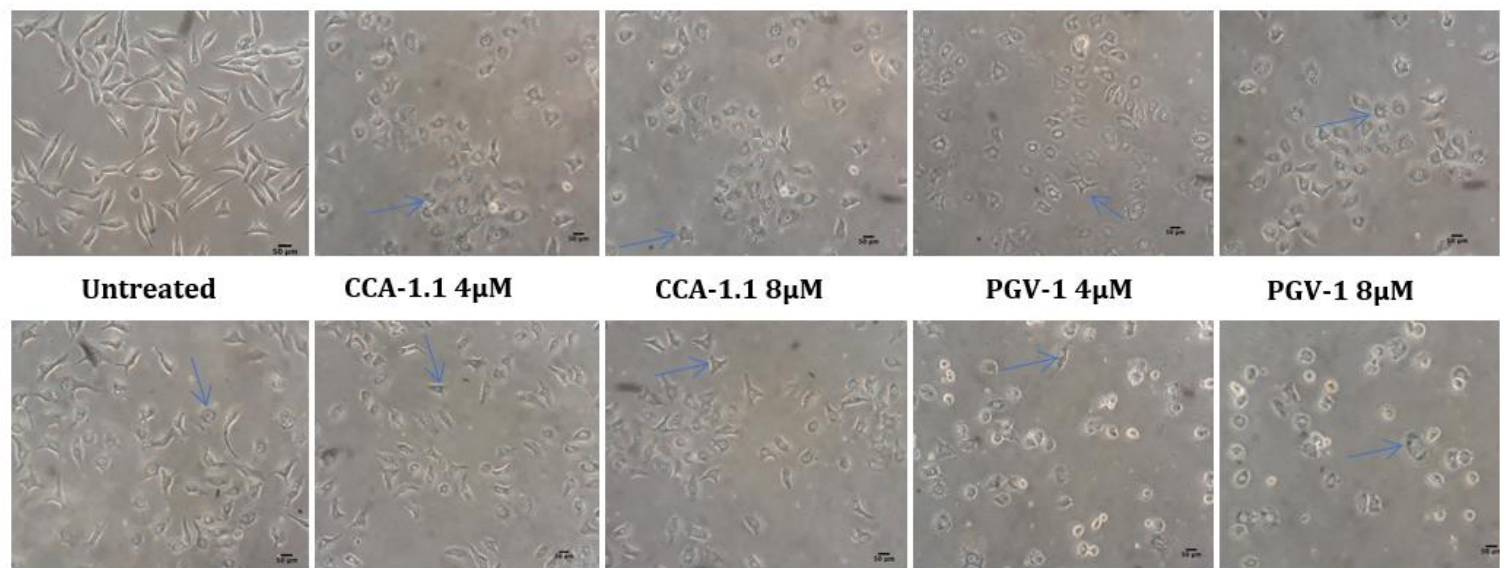

CCA-1.1 $4 \mu \mathrm{M}$

CCA-1.1 8 $\mu \mathrm{M}$

PGV-1 4 $\mu$ M

PGV-1 8 $\mu$ M
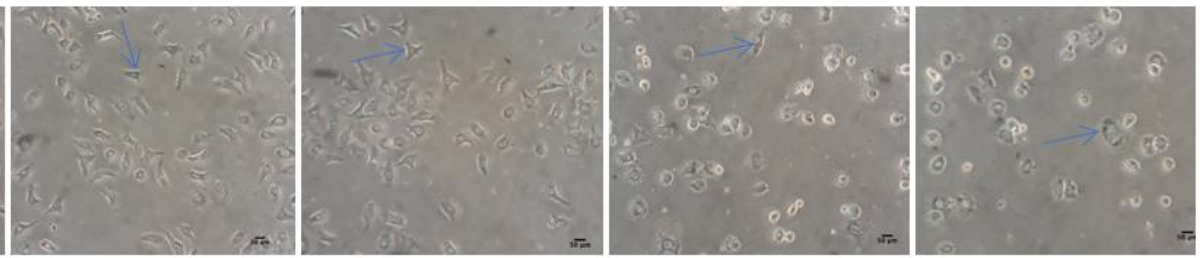

Dox 100nM

CCA-1.1 $4 \mu \mathrm{M}$

+ dox

CCA-1.1 $8 \mu \mathrm{M}$ + dox

PGV-1 4 $\mu \mathrm{M}+$

dox

PGV-1 8 $\mu \mathrm{M}+$

dox

(B)

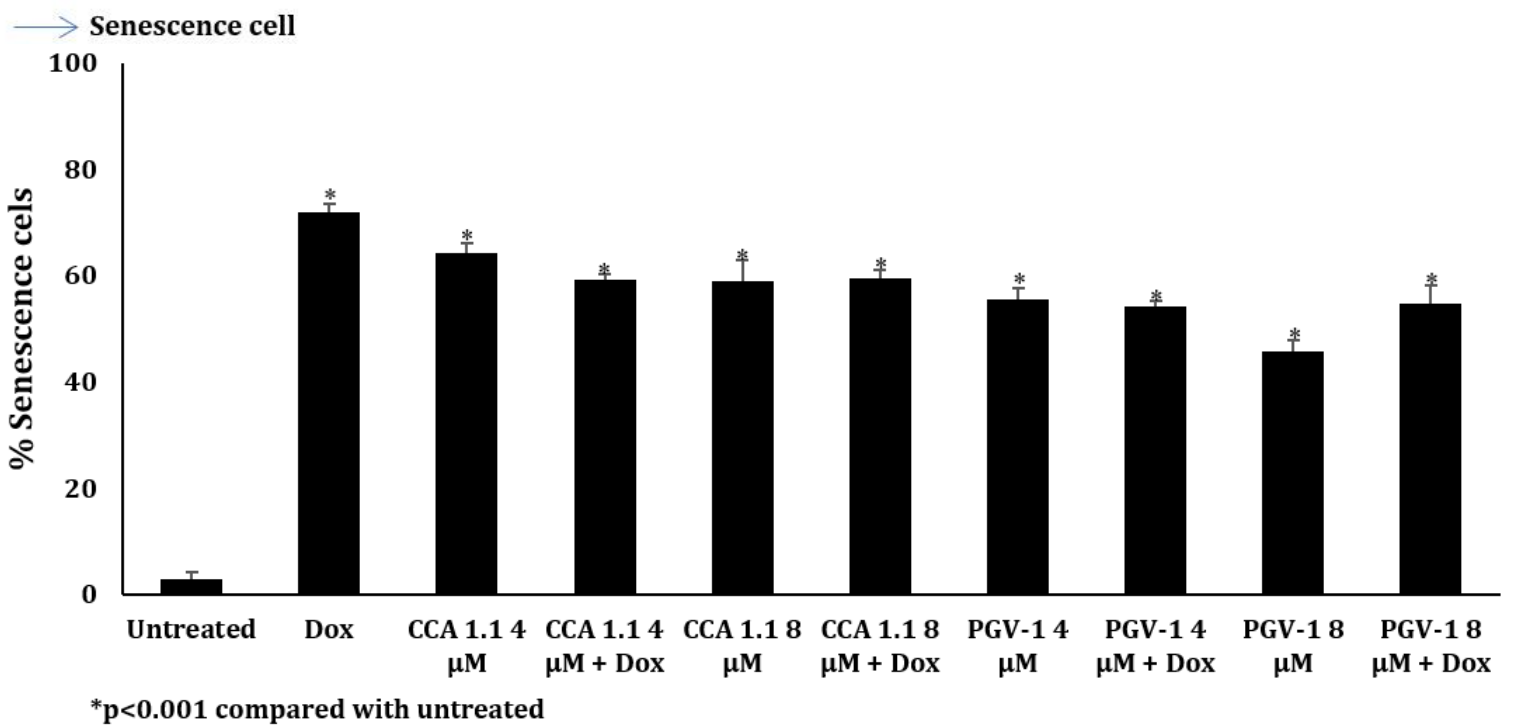

Figure 6. Induction of senescence in T47D cells following treatment with CCA-1.1, PGV-1, or CCA-1.1 + doxorubicin (Dox) treatment. Senescent cells were determined using SA- $\beta$ galactosidase (Gal) staining assay. Cells $\left(1 \times 10^{5}\right.$ cells $\left./ \mathrm{mL}\right)$ were treated with CCA-1.1 or PGV- 1 for $24 \mathrm{~h}$ and then subjected to SA- $\beta$-Gal staining. The percentage of senescent cells (i.e., $\beta$-Gal-positive cells, indicated by blue arrows) was calculated. (A) Cell morphology and (B) percentage of senescent cells. The data are presented as mean \pm standard deviation $(n=3)$. Differences between treatment groups and untreated group were analyzed using Student's $t$-test $\left({ }^{*} p<0.001\right)$.

Evaluation of cell apoptosis using annexin-V staining revealed that CCA-1.1 alone induces apoptotic effects that far exceed those of Dox. Combination treatment yielded apoptotic effects similar to those induced by CCA-1.1 alone. Differences in the present results may be attributed to differences in the sensitivity of the test systems used to determine cell cycle profiles and apoptosis (Zhao et al., 2019). The test system used to assess the cell cycle of T47D cells is appropriate for observing cell distributions in the G1, S, and G2/M phases (Pozarowski and Darzynkiewicz, 2004). By comparison, the annexin-V system evaluates changes in membrane dynamics characterizing apoptosis, which means its results are highly specific for assessing apoptosis (Darzynkiewicz et al., 2001). The results reveal that the extent of cell apoptosis induced by the combination treatment is due more to the effects of CCA-1.1 than to those of Dox. Thus, CCA-1.1 plays an essential role in enhancing cytotoxic effects, both as a single treatment and in combination with other treatments. 


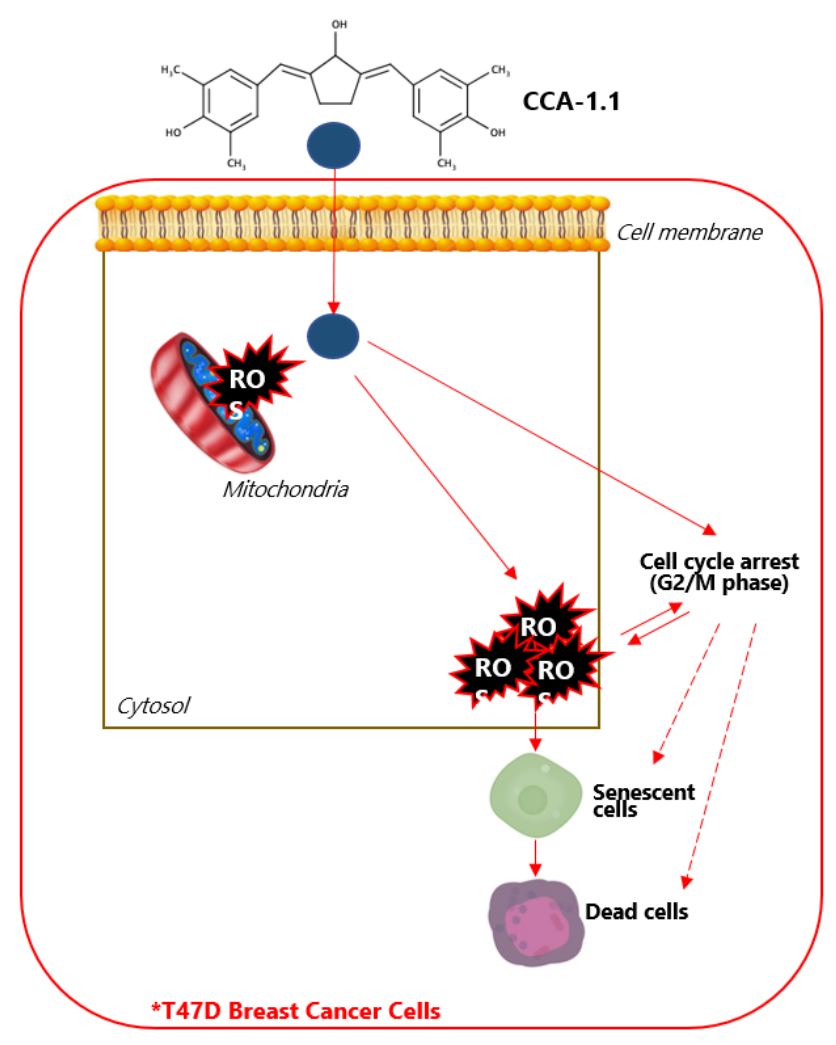

Figure 7. The proposed cytotoxic mechanism of CCA-1.1 in T47D breast cancer cells.

Interestingly, CCA-1.1 results in more substantial apoptotic effects than PGV-1 after $24 \mathrm{~h}$ of treatment. The selectivity of PGV-1 has been previously established (Lestari et al., 2019), distinguishing between its actions in cancer cells and the maintenance of healthy cells in vitro and in vivo, as well as CCA-1.1, revealed to be less cytotoxic to NIH-3T3 (Utomo et al., 2020), healthy cells. These results reveal that CCA-1.1 is an excellent candidate for development into a new selective anticancer agent.

Observation of the effect of the treatments on cell cycle progression revealed slightly different phenomena between PGV-1 and CCA-1.1. CCA-1.1 causes more cell accumulation in the G2/M phase than PGV-1 but is less visible with polyploidy cells than PGV-1. Polyploidy phenomena by chemotherapeutic agents on T47D cells are common evidence and can be caused by cells failing to do cytokinesis (Da'i et al., 2007; Otto, 2007). PGV-1 has been reported to exert polyploidy effects on T47D cells (Da'i et al., 2007). Whether this effect indicates that CCA-1.1 has more substantial effects on $\mathrm{G} 2 / \mathrm{M}$ phase cycle cell arrest than PGV-1 requires further clarification. However, because the apoptotic effect of CCA-1.1 appears to be more extensive than that PGV-1, it seems that the effect of cell cycle arrest by CCA-1.1 will directly cause apoptosis. Termination of the cell cycle in the G2/M phase by PGV-1 treatment allows cells to undergo partial mitosis without cytokinesis (Lestari et al., 2019; Meiyanto et al., 2019). The difference in the effects of the treatments on cell cycle arrest demonstrates that CCA-1.1 is more effective in stimulating apoptosis than PGV-1. Besides its strong effect on inducing apoptosis, CCA-1.1 also has remarkable effects on cell cycle arrest in the G2/M phase. This effect was observed after treatment for $24 \mathrm{~h}$ and may be expected to become more extensive when the incubation time is increased.

The potent cytotoxicity of CCA-1.1 was further illustrated by the treatment's ability to increase intracellular ROS levels and enhance senescence in T47D cells (Figure 7). Cytotoxic effects are associated with the disturbance of several ROS metabolic enzymes, which results in ROS accumulation in cells, increased stress 
environments, and, finally, cell death (Larasati et al., 2018). Compared with Dox alone and in combination with CCA-1.1 $(8 \mu \mathrm{M})$, co-treatment of Dox with CCA-1.1 $(4 \mu \mathrm{M})$ yielded the highest ROS levels. The difference in ROS level between the two treatments may be due to the prompt occurrence of apoptosis after treatment with a higher concentration of CCA-1.1 in the combination treatment. Evaluation of cell apoptosis indicated that the effects of CCA-1.1 dominate those of Dox. This finding is in line with a previous study that revealed that PGV-1 could effectively elevate ROS levels much faster (2-4-hours) than curcumin (Larasati et al., 2018; Lestari et al., 2019; Meiyanto et al., 2019). All treatments induced the same level of senescence. This finding supports the supposition that increased ROS and senescence occur before apoptosis, and those pieces of evidence have a close relationship. Because the ability of curcumin derivatives to elevate intracellular ROS contributes to their cytotoxic effects on cancer cells (Nakamae et al., 2019), the selectivity and interactions of CCA-1.1 with ROS metabolic enzymes must be studied further.

Since we used T47D cells, which are also characterized with ER-positive and found in over $70 \%$ of all cancer cases (Yu et al., 2017), CCA-1.1 needed to be elaborated more for its molecular mechanism because several types of cells had different characteristics for their cell signaling (Holliday \& Speirs, 2011). Dox is a chemotherapeutic agent often used to treat ER+ breast cancer (Ponnusamy et al., 2017). Unfortunately, because cancers are highly persistent, further improvements in therapy, including chemotherapeutic treatments, endocrine therapy, and targeted therapy, are necessary. Physiological estrogen levels have been reported to limit the cytotoxic effects of Dox and may confer cancer cells with chemotherapeutic resistance (Kelly et al., 2017; Pritchard et al., 2012). PGV-1, a lead compound based on curcumin, is a phytoestrogen that may bind to specific ERs in some tissues, either activating or down-regulating cellular responses to be a natural selective ER modulators (SERMs) (Hallman et al., 2017). Curcumin also presents anticancer activity by interrupting estrogen signaling in cancer cells through encounter cell proliferation effect and downregulated the tumor suppressor protein (Hallman et al., 2017). CCA-1.1 shows excellent anticancer effects and chemical properties and may be expected to mimic the anticancer activity of curcumin in ER+ breast cancer cells. A previous study reported that CCA-1.1 has better interactions with ER compared with PGV-1, likely because the former features a hydroxyl group that could form hydrogen bonds with ER in its cyclic structure, thereby leading to enhanced affinity (Utomo et al., 2020). Whether CCA-1.1 exerts antagonist effects on ER signaling, similar to curcumin, should be further explored. Overall, our findings suggest that CCA-1.1 alone and in combination with Dox induces more extensive apoptosis in T47 cells than PGV-1. Thus, the new curcumin analog may be developed as a chemotherapeutic/co-chemotherapeutic candidate for ER+ breast cancer therapy.

\section{CONCLUSION}

Overall, our findings suggest that CCA-1.1 alone and in combination with Dox induces more extensive apoptosis in T47 cells than PGV-1. Thus, the new curcumin analog may be developed as a chemotherapeutic/co-chemotherapeutic candidate for ER+ breast cancer therapy.

\section{ACKNOWLEDGMENT}

The authors thank the Master Program of Education Leading to Doctoral Degree for Excellent Graduates (PMDSU), Ministry of Research, Technology, and Higher Education, the Republic of Indonesia, for funding this work. The authors are also grateful to the Center for Research and Development of Medicinal Plants and Traditional Medicine (B2P2T00T), Tawangmangu, Karanganyar, Indonesia, for facilitating the flow cytometric assays.

\section{REFERENCES}

Abbas, T., Keaton, M. A., \& Dutta, A. (2013). Genomic Instability in Cancer. Cold Spring Harbor Perspectives in Biology, 5(3), a012914a012914.

https://doi.org/10.1101/cshperspect.a01 2914

Baar, M. P., Brandt, R. M. C., Putavet, D. A., Klein, J. D. D., Derks, K. W. J., Bourgeois, B. R. M., Stryeck, S., Rijksen, Y., van Willigenburg, H., Feijtel, D. A., van der Pluijm, I., Essers, J., van Cappellen, W. A., van IJcken, W. F., Houtsmuller, A. B., Pothof, J., de Bruin, R. W. F., Madl, T., Hoeijmakers, J. H. J., ... de Keizer, P. L. J. (2017). Targeted Apoptosis of Senescent Cells Restores Tissue Homeostasis in Response to Chemotoxicity and Aging. Cell, 169(1), 132-147.e16. 
https://doi.org/10.1016/j.cell.2017.02.03 1

Bandyopadhyay, A., Wang, L., Agyin, J., Tang, Y., Lin, S., Yeh, I.-T., De, K., \& Sun, L.-Z. (2010). Doxorubicin in Combination with a Small TGFb Inhibitor: A Potential Novel Therapy for Metastatic Breast Cancer in Mouse Models. PLoS ONE, 5(4), 13. https://doi.org/10.1371/journal.pone.00 10365

Bates, D., \& Eastman, A. (2017). Microtubule destabilising agents: Far more than just antimitotic anticancer drugs: MDA mechanisms of action. British Journal of Clinical Pharmacology, 83(2), 255-268. https://doi.org/10.1111/bcp.13126

Chen, Z. J., \& Ni, Z. (2006). Mechanisms of genomic rearrangements and gene expression changes in plant polyploids. BioEssays, 28(3), 240-252. https://doi.org/10.1002/bies.20374

Da'i, M., Jenie, U. A., AM, S., Kawaichi, M., \& Meiyanto, E. (2007). T47D cells arrested at G2M and Hyperploidy Formation Induced by a Curcumin's Analogue PGV-1. Indonesian Journal of Biotechnology, 12(2), 1005-1012. https://doi.org/10.22146/ijbiotech.7776

Darzynkiewicz, Z., Bedner, E., \& Smolewski, P. (2001). Flow Cytometry in Analysis of Cell Cycle and Apoptosis. Seminars in Hematology, 38(2), 179-193. https://doi.org/10.1052/shem.2001.219 29

Fernandez, P., Burghardt, R., Smith, R., Nodland, K., \& Safe, S. (1994). High passage T47D human breast cancer cells: Altered endocrine and 2,3,7,8-tetrachlorodibenzop-dioxin responsiveness. European Journal of Pharmacology: Environmental Toxicology and Pharmacology, 270(1), 53$65 . \quad$ https://doi.org/10.1016/09266917(94)90080-9

Griffith, O. L., Spies, N. C., Anurag, M., Griffith, M., Luo, J., Tu, D., Yeo, B., Kunisaki, J., Miller, C. A., Krysiak, K., Hundal, J., Ainscough, B. J., Skidmore, Z. L., Campbell, K., Kumar, R., Fronick, C., Cook, L., Snider, J. E., Davies, S., ... Ellis, M. J. (2018). The prognostic effects of somatic mutations in ER-positive breast cancer. Nature Communications, 9(1), 3476. https://doi.org/10.1038/s41467018-05914-X
Hallman, K., Aleck, K., Dwyer, B., Lloyd, V., Quigley, M., Sitto, N., Siebert, A. E., \& Dinda, S. (2017). The effects of turmeric (curcumin) on tumor suppressor protein (p53) and estrogen receptor (ER\&alpha;) in breast cancer cells. Breast Cancer: Targets and Therapy, Volume 9, 153-161. https://doi.org/10.2147/BCTT.S125783

Hermawan, A., Fitriasari, A., Junedi, S., Ikawati, M., Haryanti, S., Widaryanti, B., Da'i, M., \& Meiyanto, E. (2011). PGV-0 and PGV-1 Increased Apoptosis Induction of Doxorubicin on MCF-7 Breast Cancer Cells. PHARMACON, 12(2), 55-59. https://doi.org/10.23917/pharmacon.v1 $2 \mathrm{i} 2.32$

Holliday, D. L., \& Speirs, V. (2011). Choosing the right cell line for breast cancer research. Breast Cancer Research, 13(4). https://doi.org/10.1186/bcr2889

Kao, J., Salari, K., Bocanegra, M., Choi, Y.-L., Girard, L., Gandhi, J., Kwei, K. A., HernandezBoussard, T., Wang, P., Gazdar, A. F., Minna, J. D., \& Pollack, J. R. (2009). Molecular Profiling of Breast Cancer Cell Lines Defines Relevant Tumor Models and Provides a Resource for Cancer Gene Discovery. PLoS ONE, 4(7), e6146. https://doi.org/10.1371/journal.pone.00 06146

Kelly, P., Ma, Z., Baidas, S., Moroose, R., Shah, N., Dagan, R., Mamounas, E., \& Rineer, J. (2017). Patterns of Progression in Metastatic Estrogen Receptor Positive Breast Cancer: An Argument for Local Therapy. International Journal of Breast Cancer, 2017, 1-8. https://doi.org/10.1155/2017/1367159

Lal, S., McCart Reed, A. E., de Luca, X. M., \& Simpson, P. T. (2017). Molecular signatures in breast cancer. Methods, 131, 135-146. https://doi.org/10.1016/j.ymeth.2017.06 .032

Larasati, Y. A., Yoneda-Kato, N., Nakamae, I., Yokoyama, T., Meiyanto, E., \& Kato, J. (2018). Curcumin targets multiple enzymes involved in the ROS metabolic pathway to suppress tumor cell growth. Scientific Reports, 8(1). https://doi.org/10.1038/s41598-01820179-6

Lee, S. J., \& Langhans, S. A. (2012). Anaphasepromoting complex/cyclosome protein $\mathrm{Cdc} 27$ is a target for curcumin-induced cell 
cycle arrest and apoptosis. BMC Cancer, 12(1), 44. https://doi.org/10.1186/14712407-12-44

Lestari, B., Nakamae, I., Yoneda-Kato, N., Morimoto, T., Kanaya, S., Yokoyama, T., Shionyu, M., Shirai, T., Meiyanto, E., \& Kato, J. (2019). Pentagamavunon-1 (PGV-1) inhibits ROS metabolic enzymes and suppresses tumor cell growth by inducing $M$ phase (prometaphase) arrest and cell senescence. Scientific Reports, 9(1), 14867. https://doi.org/10.1038/s41598-01951244-3

Meiyanto, E., Agustina, D., Am, S., \& Da'i, M. (2007). PGV-0 Induces Apoptosis on T47d Breast Cancer Cell Line Through Caspase-3 Activation. Jurnal Kedokteran Yarsi, 2, 11.

Meiyanto, E., Putri, D. D. P., Susidarti, R. A., Murwanti, R., Sardjiman, S., Fitriasari, A., Husnaa, U., Purnomo, H., \& Kawaichi, M. (2014). Curcumin and its Analogues (PGV0 and PGV-1) Enhance Sensitivity of Resistant MCF-7 Cells to Doxorubicin through Inhibition of HER2 and NF-kB Activation. Asian Pacific Journal of Cancer Prevention, 15(1), 179-184. https://doi.org/10.7314/APJCP.2014.15. 1.179

Meiyanto, E., Putri, H., Larasati, Y. A., Utomo, R. Y., Jenie, R. I., Ikawati, M., Lestari, B., YonedaKato, N., Nakamae, I., Kawaichi, M., \& Kato, J.-Y. (2019). Anti-proliferative and Antimetastatic Potential of Curcumin Analogue, Pentagamavunon-1 (PGV-1), Toward Highly Metastatic Breast Cancer Cells in Correlation with ROS Generation. Advanced Pharmaceutical Bulletin, 9(3), 445-452. https://doi.org/10.15171/apb.2019.053

Meiyanto, E., Septisetyani, E. P., Larasati, Y. A., \& Kawaichi, M. (2018). Curcumin Analog Pentagamavunon-1 (PGV-1) Sensitizes Widr Cells to 5-Fluorouracil through Inhibition of NF-kB Activation. Asian Pacific Journal of Cancer Prevention, 19(1), 49-56.

https://doi.org/10.22034/APJCP.2018.19 .1 .49

Nakamae, I., Morimoto, T., Shima, H., Shionyu, M., Fujiki, H., Yoneda-Kato, N., Yokoyama, T., Kanaya, S., Kakiuchi, K., Shirai, T., Meiyanto, E., \& Kato, J. (2019). Curcumin Derivatives Verify the Essentiality of ROS Upregulation in Tumor Suppression.
Molecules, $24(22)$,
https://doi.org/10.3390/molecules24224
067

Otto, S. P. (2007). The Evolutionary Consequences of Polyploidy. Cell, 131(3), 452-462. https://doi.org/10.1016/j.cell.2007.10.02 2

Ponnusamy, L., Mahalingaiah, P. K. S., \& Singh, K. P. (2017). Treatment schedule and estrogen receptor-status influence acquisition of doxorubicin resistance in breast cancer cells. European Journal of Pharmaceutical Sciences, $\quad 104$, 424-433. https://doi.org/10.1016/j.ejps.2017.04.0 20

Pozarowski, P., \& Darzynkiewicz, Z. (2004). Analysis of Cell Cycle by Flow Cytometry. In A. H. Sch nthal, Checkpoint Controls and Cancer (Vol. 281, pp. 301-312). Humana Press. https://doi.org/10.1385/1-59259-811$0: 301$

Pritchard, J. E., Dillon, P. M., Conaway, M. R., Silva, C. M., \& Parsons, S. J. (2012). A Mechanistic Study of the Effect of Doxorubicin/Adriamycin on the Estrogen Response in a Breast Cancer Model. Oncology, 83(6), 305-320. https://doi.org/10.1159/000341394

Ray, P. D., Huang, B.-W., \& Tsuji, Y. (2012). Reactive oxygen species (ROS) homeostasis and redox regulation in cellular signaling. Cellular Signalling, 24(5), 981-990. https://doi.org/10.1016/j.cellsig.2012.01. 008

Reynolds, C. P., \& Maurer, B. J. (2005). Evaluating Response to Antineoplastic Drug Combinations in Tissue Culture Models. In R. D. Blumenthal, Chemosensitivity (Vol. 110, pp. 173-184). Humana Press. https://doi.org/10.1385/1-59259-8692:173

Shah, M. A., \& Schwartz, G. K. (2001). Cell Cyclemediated Drug Resistance: An Emerging Concept in Cancer Therapy. 7, 2168-2181. https://clincancerres.aacrjournals.org/co ntent/7/8/2168.full-text.pdf

Tacar, O., Sriamornsak, P., \& Dass, C. R. (2013). Doxorubicin: An update on anticancer molecular action, toxicity and novel drug delivery systems: Doxorubicin cell and molecular biological activity. Journal of Pharmacy and Pharmacology, 65(2), 157- 
170. https://doi.org/10.1111/j.20427158.2012.01567.x

Utomo, R. Y., Wulandari, F., Novitasari, D., Lestari, B., Susidarti, R. A., Jenie, R. I., Kato, J., Sardjiman, \& Edy Meiyanto. (2020). Preparation and cytotoxic evaluation of PGV-1 derivative, CCA-1.1, as a new curcumin analog with improvedphysicochemical and pharmacological properties. Manuscript Submitted for Publication.

Wulandari, F., Novitasari, D., Ikawati, M., Kirihata, M., Kato, J.-Y., \& Meiyanto, E. (2020). A New Curcumin Analog, CCA-1.1, Induces Cell Death and Cell Cycle Arrest in WiDr Colon Cancer Cells via ROS Generation. Submited to Publication.
Yu, S., Kim, T., Yoo, K. H., \& Kang, K. (2017). The T47D cell line is an ideal experimental model to elucidate the progesteronespecific effects of a luminal A subtype of breast cancer. Biochemical and Biophysical Research Communications, 486(3), 752758.

https://doi.org/10.1016/j.bbrc.2017.03.1 14

Zhao, M. L., Rabiee, A., Kovary, K. M., BahramiNejad, Z., Taylor, B., \& Teruel, M. N. (2019). Molecular competition in G1 controls when cells simultaneously commit to terminally differentiate and exit the cell-cycle [Preprint]. Cell Biology. https://doi.org/10.1101/632570 